\title{
Elimination of Heparin Interference During Microarray Processing of Fresh and Biobank-Archived Blood Samples
}

Citation for published version (APA):

Hebels, D. G. A. J., van Herwijnen, M. H. M., Brauers, K. J. J., de Kok, T. M. C. M., Chalkiadaki, G., Kyrtopoulos, S. A., \& Kleinjans, J. C. S. (2014). Elimination of Heparin Interference During Microarray Processing of Fresh and Biobank-Archived Blood Samples. Environmental and Molecular Mutagenesis, 55(6), 482-491. https://doi.org/10.1002/em.21869

Document status and date:

Published: 01/07/2014

DOI:

10.1002/em.21869

Document Version:

Publisher's PDF, also known as Version of record

Document license:

Taverne

Please check the document version of this publication:

- A submitted manuscript is the version of the article upon submission and before peer-review. There can be important differences between the submitted version and the official published version of record.

People interested in the research are advised to contact the author for the final version of the publication, or visit the DOI to the publisher's website.

- The final author version and the galley proof are versions of the publication after peer review.

- The final published version features the final layout of the paper including the volume, issue and page numbers.

Link to publication

\footnotetext{
General rights rights.

- You may freely distribute the URL identifying the publication in the public portal. please follow below link for the End User Agreement:

www.umlib.nl/taverne-license

Take down policy

If you believe that this document breaches copyright please contact us at:

repository@maastrichtuniversity.nl

providing details and we will investigate your claim.
}

Copyright and moral rights for the publications made accessible in the public portal are retained by the authors and/or other copyright owners and it is a condition of accessing publications that users recognise and abide by the legal requirements associated with these

- Users may download and print one copy of any publication from the public portal for the purpose of private study or research.

- You may not further distribute the material or use it for any profit-making activity or commercial gain

If the publication is distributed under the terms of Article $25 \mathrm{fa}$ of the Dutch Copyright Act, indicated by the "Taverne" license above, 


\title{
Research Article
}

\section{Elimination of Heparin Interference During Microarray Processing of Fresh and Biobank-Archived Blood Samples}

\author{
Dennie G.A.J. Hebels, ${ }^{1}{ }^{*}$ Marcel H.M. van Herwijnen, ${ }^{1}$ Karen J.J. Brauers, ${ }^{1}$ \\ Theo M.C.M. de Kok, ${ }^{1}$ Georgia Chalkiadaki, ${ }^{2}$ Soterios A. Kyrtopoulos, ${ }^{3}$ and \\ Jos C.S. Kleinjans ${ }^{1}$ \\ ${ }^{1}$ Department of Toxicogenomics, Maastricht University, Universiteitssingel 50, \\ 6229 ER Maastricht, The Netherlands \\ ${ }^{2}$ Department of Social Medicine, School of Medicine, University of Crete, \\ Voutes, Heraklion 71003, Crete, Greece \\ ${ }^{3}$ National Hellenic Research Foundation, Institute of Biology, Division of \\ Organic and Medicinal Chemistry, Medicinal Chemistry and Biotechnology, \\ 48 Vas Constantinou Avenue, Athens 116 35, Greece
}

\begin{abstract}
In the context of environmental health research, biobank blood samples have recently been identified as suitable for high-throughput omics analyses enabling the identification of new biomarkers of exposure and disease. However, blood samples containing the anti-coagulant heparin could complicate transcriptomic analysis because heparin may inhibit RNA polymerase causing inefficient cRNA synthesis and fluorophore labelling. We investigated the inhibitory effect of heparin and the influence of storage conditions 10 or $3 \mathrm{hr}$ bench times, storage at room temperature or $-80^{\circ} \mathrm{C}$ ) on fluorophore labelling in heparinized fresh human buffy coat and whole blood biobank samples during the mRNA work-up protocol for microarray analysis. Subsequently, we removed heparin by lithium chloride (LiCl) treatment and performed a quality control analysis of $\mathrm{LiCl}$-treated biobank sample microarrays to prove their suitability for downstream data analysis. Both fresh and bio-

bank samples experienced varying degrees of heparin-induced inhibition of fluorophore labelling, making most samples unusable for microarray analysis. RNA derived from EDTA and citrate blood was not inhibited. No effect of bench time was observed but room temperature storage gave slightly better results. Strong correlations were observed between original blood sample RNA yield and the amount of synthesized cRNA. LiCl treatment restored sample quality to normal standards in both fresh and biobank samples and the previously identified correlations disappeared. Microarrays hybridized with LiCl-treated biobank samples were of excellent quality with no identifiable influence of heparin. We conclude that, to obtain high quality results, in most cases heparin removal is essential in blood-derived RNA samples intended for microarray analysis. Environ. Mol. Mutagen. 55:482-491, 2014. @ 2014 Wiley Periodicals, Inc.
\end{abstract}

Key words: heparin interference; blood; biobank samples; transcriptomics; lithium chloride treatment; fluorophore PCR labelling

\section{INTRODUCTION}

In biomedical research, omics technologies have greatly contributed to the discovery of biomarkers and improved our understanding of disease mechanisms. Biobanks represent herein a precious resource for human long-term storage specimens [Ellinger-Ziegelbauer et al., 2009; McHale et al., 2010]. Omics research is especially relevant in generating new biomarkers from biobank material because we have recently shown, in the context of the European EnviroGenomarkers project (http://www. envirogenomarkers.net), that a large fraction of human
Additional Supporting Information may be found in the online version of this article.

Grant sponsor: EnviroGenomarkers (a part of the European Union Seventh Framework); Grant number: 226756.

*Correspondence to: Dennie G.A.J. Hebels. E-mail: d.hebels@maastrichtuniversity.nl

Received 27 January 2014; provisionally accepted 27 March 2014; and in final form 1 April 2014

DOI 10.1002/em.21869

Published online 17 April 2014 in

Wiley Online Library (wileyonlinelibrary.com). 
blood-derived samples currently in long-term biobank storage in the absence of stabilizing agents is suitable for analysis using high throughput omics technologies [Hebels et al., 2013]. This includes the application of transcriptomic analysis using high quality RNA from blood samples, something that was previously not thought possible without collection and storage in the presence of an RNA preservative. Application of these powerful technologies to biological samples collected during previous decades in the context of population-based or diseaseoriented cohorts is thus possible. By combining this with other available information from these cohorts (e.g., environmental exposure, dietary or lifestyle habits, disease status), such application is likely to provide an important contribution to research on mechanisms of disease.

A large fraction of available biobank samples consists of whole blood drawn in anti-coagulant-containing tubes, such as citrate, EDTA, and heparin. All three anticoagulants have been shown to yield more than satisfactory results in downstream omics applications [Hebels et al., 2013]. We have, however, recently come across an interfering influence of heparin during the work-up of samples intended for transcriptomic analysis, which may cause technical problems in some biobank-stored blood samples collected in heparin tubes. Although it is our experience that heparin-containing blood samples consistently generate high quality RNA with a high yield, downstream applications may be subject to heparininduced inhibition of crucial enzymes. Heparin has long been known to inhibit polymerase chain reaction (PCR) in DNA samples, and there have been several publications describing this phenomenon [Walter et al., 1967; Beutler et al., 1990; Goulian and Heard, 1990; Holodniy et al., 1991; Satsangi et al., 1994; Yokota et al., 1999]. Heparin is a highly anionic glycosaminoglycan, and its negative charges allow it to bind to lysine and arginine residues in the DNA binding sites of the polymerase enzyme, thereby preventing efficient replication [Berg et al., 2002]. Its chemical properties, which resemble nucleic acids, explain why commonly used DNA or RNA purification columns are incapable of efficiently removing heparin from the sample [Amersham Biosciences. 2003; Johnson et al., 2003]. The inhibiting effect of heparin has been described for DNA and RNA polymerases, reverse transcriptase, restriction enzymes, and also differs depending on the type of DNA polymerase, with alpha and delta forms being extremely sensitive whereas the beta and gamma forms are resistant [Walter et al., 1967; Goulian and Heard, 1990; Coad et al., 1992; Todd and Buccini, 1993; Gerard, 1994; Bai et al., 2000]. The degree of inhibition is also proportional to the concentration of heparin and decreases when blood cells are first washed or the amount of DNA in the sample is high [Taylor, 1997; Yokota et al., 1999]. Although the inhibitory effect of heparin on enzyme activity has been well established, and sample preparation for microarray analysis uses reverse transcriptase and polymerase, as far as we know, there are no publications that describe analogous effects during microarray work-up. In fact, fluorophore or biotin labelling protocols for blood-derived RNA of commonly used microarray manufacturers (e.g., Agilent Technologies, Affymetrix ${ }^{\circledR}$, NimbleGen, etc.) do not mention the possible negative effect of heparin. Based on our observations and those of others [Satsangi et al., 1994], fresh heparin blood samples that are not frozen before RNA isolation are subject to less influence from heparin than frozen samples. However, we have also experienced that long-term frozen heparin blood samples do not always suffer from interference by heparin during fluorophore labelling. This inconsistent manifestation of heparin-induced inhibition contributes to the absence of literature on the subject.

There are several ways of removing heparin from nucleic acid samples, including heparinase treatment, ionexchange resin treatment, and lithium chloride $(\mathrm{LiCl})$ precipitation, the latter of which is the cheapest and fastest method available, and all of which successfully enable PCR assays again with purified DNA or RNA [Poli et al., 1993; Jung et al., 1997; Taylor, 1997; del Prete et al., 2007; Wang et al., 2007]. Although these methods are usually used in standard PCR or RT-PCR assays, it seems likely that they would also be effective in removing heparin from RNA samples intended for fluorophore labelling. Using such heparin clean-up techniques could thus be of great importance for both freshly isolated and long-term storage biobank blood samples to be used for transcriptomic analysis.

It is the purpose of this report to (a) describe the inhibitory effect of heparin and the influence of storage conditions on the fluorophore labelling process in fresh as well as archived human buffy coat or whole blood samples during the mRNA work-up protocol for microarray analysis (Agilent Technologies), (b) provide a solution to this problem by applying $\mathrm{LiCl}$ treatment, and (c) present a short quality control analysis of biobank-derived heparin blood-based microarrays to prove their suitability for downstream data analysis. In addition, with this study we intend to put new focus on this issue with the aim of increasing opportunities for investigating transcriptomics in valuable human blood samples and preventing costly mistakes.

\section{MATERIAL AND METHODS}

\section{Sample Collection}

To illustrate the inhibitory effect of heparin, we collected fresh blood samples to investigate the short-term effect of freezing and storage at $-80^{\circ} \mathrm{C}$ versus direct processing. Two $10 \mathrm{ml}$ heparin blood tubes (BD Vacutainer, Breda, The Netherlands) were drawn from four volunteers (two male, ages 24 and 29, and two female, ages 32 and 34). The first 
tube of each volunteer was processed immediately while the second tube was left at room temperature (RT) for $3 \mathrm{hr}$ before processing to investigate the effect of bench time. Processing consisted of centrifugation at $1,500 \mathrm{~g}$ for $10 \mathrm{~min}$ at RT and isolation of the buffy coat, which was subsequently split up into two equal parts of $400 \mu$ one of which was stored at $-80^{\circ} \mathrm{C}$ and the other was used immediately for RNA isolation. The total number of samples was thus 16 (i.e., both bench times and storage temperatures for all four subjects). RNA from frozen buffy coats was isolated after $72 \mathrm{hr}$.

In a separate experiment, we collected fresh blood samples from another four volunteers (two male, ages 28 and 44, and two female, ages 22 and 30 ) in one $10 \mathrm{ml}$ EDTA and two $4.5 \mathrm{ml}$ sodium citrate tubes (BD Vacutainer) to demonstrate that PCR inhibition is heparin-specific. EDTA and citrate blood were split up into two equal parts of $200 \mu 1$ (the two citrate tubes were first mixed), and the first part was processed immediately while the second part was left at RT for $3 \mathrm{hr}$ (total $n=8$ ). Buffy coats were prepared as described above and samples were subsequently stored at $-80^{\circ} \mathrm{C}$ for $72 \mathrm{hr}$ until RNA isolation.

The effect of heparin in biobank samples was assessed using whole blood samples from one of the participating biobanks within the EnviroGenomarkers consortium, i.e., the Rhea project, which represents a prospective mother-child study in the prefecture of Heraklion, Crete, Greece [Chatzi et al., 2009]. Whole blood from the umbilical cord and corresponding 4-year follow-up venipuncture blood samples from the same children were collected in standard heparin blood tubes and kept at $4{ }^{\circ} \mathrm{C}$ until further processing. A volume of $400 \mu \mathrm{l}$ of whole blood was mixed with $1.2 \mathrm{ml}$ of RNAlater (Life Technologies-Ambion ${ }^{\circledR}$ ) and subsequently stored at $-80^{\circ} \mathrm{C}$ for varying periods of time. Samples were transported on dry ice to Maastricht University and a subset of 24 samples (12 cord/follow-up sample pairs) was used for further analysis.

\section{RNA Isolation}

RNA extraction from frozen buffy coats was performed by thawing approximately 400 or $200 \mu \mathrm{l}$ of buffy coat (see Sample collection above) while fully immersed in $1.2 \mathrm{ml}$ of RNAlater and subsequently extracting RNA by column purification according to the manufacturer's instructions, including a DNase I digestion to remove DNA (RiboPure ${ }^{\mathrm{TM}}$-Blood Kit, Life Technologies-Ambion $\left.{ }^{\circledR}\right)$. Unfrozen buffy coats $(400 \mu \mathrm{l})$ were mixed with $1.2 \mathrm{ml}$ of RNAlater immediately followed by extraction, while RNAlater-containing frozen whole blood cord and follow-up samples were thawed at RT followed by extraction. Cord samples were extracted between May and July 2009. The 4-year follow-up samples were extracted in November and December 2012. On average, cord samples were stored at $-80^{\circ} \mathrm{C}$ for $482 \pm 108$ days (mean \pm standard deviation) before extraction, while follow-up samples were stored for $234 \pm 97$ days at $-80^{\circ} \mathrm{C}$ before extraction (significantly lower, $P=2.6^{*} 10^{-12}$, paired $t$-test). We quantified RNA using a Nanodrop ND-1000 spectrophotometer (Thermo Scientific, Wilmington, DE) and assessed the spectrophotometric A260/A280 and A260/A230 absorbance ratios as indicators of sample purity. An Agilent 2100 Bioanalyzer (Agilent Technologies, Amstelveen, the Netherlands) was used to assess RNA quality, including its integrity number (RIN), ranging from 1 to 10 , with a minimum of 6 being recommended for microarray analysis. RNA was stored at $-80^{\circ} \mathrm{C}$ until further processing took place, at which point cord and follow-up samples were processed simultaneously.

\section{LiCl Precipitation}

To remove heparin from the RNA samples, $\mathrm{LiCl}$ solution (concentration 7.5 M, Life Technologies-Ambion ${ }^{\circledR}$, Bleiswijk, The Netherlands, Catalog \# AM9480) was added to $1.6 \mu \mathrm{g}$ RNA of each sample at a final concentration of $2.5 \mathrm{M}$ and samples were chilled for $30 \mathrm{~min}$ at $-20^{\circ} \mathrm{C}$ followed by centrifugation at $13,000 \mathrm{~g}$ for $15 \mathrm{~min}$. The pelleted heparin- free RNA was subsequently washed with $70 \%$ ethanol and resuspended in nuclease-free water.

\section{Labelling, Hybridization, and Scanning of Microarrays}

For fluorophore labelling and microarray hybridization of samples, we followed the One Color Microarray-Based Gene Expression Analysis-Low Input Quick Amp Labeling protocol from Agilent Technologies. Briefly, labelling of samples was performed by reverse transcribing 200 ng of each RNA sample into cDNA followed by a T7 RNA polymerase reaction to synthesize cyanine 3 (Cy3)-labelled cRNA using Cy3-cytidine triphosphate (CTD) nucleosides. Four universal human reference RNA samples (Agilent Technologies, Catalog \# 740000) were also included in the labelling protocol (200 ng input RNA, average RIN: $8.7 \pm 0.1)$ as non-heparin/anti-coagulant exposed controls. Labelling was followed by hybridization of Cy3-labelled cRNA on Agilent SurePrint G3 Human Gene Expression 8x60K v2 Microarray slides which was performed only for the 24 biobank samples treated with $\mathrm{LiCl}$. After hybridization, we washed the slides and scanned them using an Agilent Technologies G2565CA DNA Microarray Scanner. The photomultiplier tube (PMT) gain was determined automatically and laser power was set to $100 \%$ and the PMT gain saturation tolerance to $0.02 \%$.

\section{Microarray Quality Control and Statistics}

Microarray probes were evaluated using a quality control pipeline that assesses the number of pixels, the mean/median intensity ratio, the saturation levels, and the foreground/background intensity ratio. Probes were defined as "good" when: (a) the spot contained at least $75 \%$ of the maximum possible number of pixels; (b) the raw mean/median ratio was above 0.9 ; (c) the difference between spot and background intensity was $>2.6$ times the standard deviation of the background intensity; (d) the number of saturated pixels was below $50 \%$. In addition, several technical aspects were evaluated based on images representing the individual microarrays, as well as on the number of high quality probes. We established the technical performance and quality of the microarrays by visual evaluation of the scan images before and after between-array normalization using the quantile normalization method [Bolstad et al., 2003].

Differences between groups were determined by paired or Student's t-test analysis and correlations were performed using Pearson's correlation coefficient. A $P$-value $<0.01$ was considered significant.

\section{RESULTS}

\section{Buffy Coat Fresh Sample Work-up and LiCl Treatment}

Buffy coats prepared from freshly drawn blood samples were used to investigate the inhibiting effect of heparin in more detail. Blood was drawn from four individuals and used to assess how differences in storage temperature (RT versus $\left.-80^{\circ} \mathrm{C}\right)$ and bench time $(0 \mathrm{hr}$ versus $3 \mathrm{hr})$ might influence the results of the fluorophore labelling process and how $\mathrm{LiCl}$ treatment can be used to improve the results. Buffy coats were used with the goal of also investigating this sample type in addition to whole blood (see biobank samples). Four RNA standards were included as non-heparin/anti-coagulant exposed controls. The results are summarized in Table I.

During RNA isolation of fresh buffy coat samples, we did not encounter any problems and RINs averaged at $8.7 \pm 0.6$, indicating high quality RNA. The 
TABLE I. Average Yields, RINs, and Labelling Efficiencies of Freshly Isolated Heparinized Buffy Coat Samples at Two Bench Times and Two Storage Temperatures

\begin{tabular}{|c|c|c|c|c|c|c|c|}
\hline & & $\begin{array}{c}\text { All samples } \\
\text { combined }(n=16)\end{array}$ & $\begin{array}{c}0 \text { hr bench } \\
\text { time }(n=8)^{\mathrm{a}}\end{array}$ & $\begin{array}{c}3 \mathrm{hr} \text { bench } \\
\text { time }(n=8)^{\mathrm{a}}\end{array}$ & $\begin{array}{l}\text { RT storage } \\
\quad(n=8)^{\mathrm{a}}\end{array}$ & $\begin{array}{c}-80^{\circ} \mathrm{C} \text { storage } \\
(n=8)^{\mathrm{a}}\end{array}$ & $\begin{array}{c}\text { Heparin-free } \\
\text { RNA reference } \\
\text { controls }(n=4)\end{array}$ \\
\hline & Buffy coat & $14.8 \pm 6.8$ & $14.0 \pm 7.6$ & $15.5 \pm 6.2$ & $17.9 \pm 6.9^{\mathrm{b}}$ & $11.6 \pm 5.2$ & $\mathrm{n} / \mathrm{a}$ \\
\hline & RNA yield $(\mu \mathrm{g})$ & & & & & & \\
\hline \multirow{2}{*}{$\begin{array}{c}\text { Without } \mathrm{LiCl} \\
\text { treatment }\end{array}$} & cRNA yield $(\mu \mathrm{g})$ & $1.3 \pm 0.7$ & $1.2 \pm 0.8$ & $1.3 \pm 0.7$ & $1.7 \pm 0.8^{\mathrm{b}}$ & $0.9 \pm 0.4$ & $5.6 \pm 0.4^{c}$ \\
\hline & 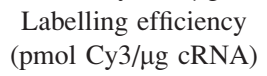 & $14.3 \pm 6.1$ & $14.6 \pm 7.4$ & $14.0 \pm 5.0$ & $10.7 \pm 1.7$ & $17.9 \pm 6.9$ & $14.6 \pm 0.5$ \\
\hline \multirow{2}{*}{$\begin{array}{l}\text { With } \mathrm{LiCl} \\
\text { treatment }\end{array}$} & cRNA yield $(\mu \mathrm{g})$ & $4.3 \pm 0.8^{\mathrm{d}}$ & $4.7 \pm 0.8^{\mathrm{d}}$ & $4.0 \pm 0.7^{\mathrm{d}}$ & $4.6 \pm 0.7^{\mathrm{d}}$ & $4.0 \pm 0.9^{\mathrm{d}}$ & - \\
\hline & 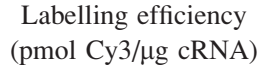 & $13.9 \pm 1.0$ & $13.8 \pm 0.9$ & $14.1 \pm 1.1$ & $13.7 \pm 1.0^{\mathrm{e}}$ & $14.2 \pm 0.9$ & - \\
\hline
\end{tabular}

${ }^{a}$ Each condition here incorporates either two storage temperatures or two bench times for all 4 subjects (i.e. $n=8$ ).

${ }^{\mathrm{b}}$ Significantly higher buffy coat RNA and cRNA yield compared with storage at $-80^{\circ} \mathrm{C}$ (paired $t$-test, $P<0.01$ ).

${ }^{\mathrm{c}}$ Significantly higher cRNA yield compared with all fresh samples combined without $\mathrm{LiCl}$ treatment $\left(\mathrm{Student}\right.$ 's $t$-test, $\left.P=1.3 * 10^{-9}\right)$. Without $\mathrm{LiCl}$ treatment 4 out of 16 fresh samples did not meet the minimum recommended cRNA yield.

${ }^{\mathrm{d} S i g n i f i c a n t l y ~ h i g h e r ~ c R N A ~ y i e l d ~ c o m p a r e d ~ w i t h ~ w i t h o u t ~} \mathrm{LiCl}$ treatment samples (paired $t$-test, $P<0.001$ ).

${ }^{\text {e}}$ Significantly higher labelling efficiency compared with without $\mathrm{LiCl}$ treatment (paired $t$-test, $P<0.01$ ).
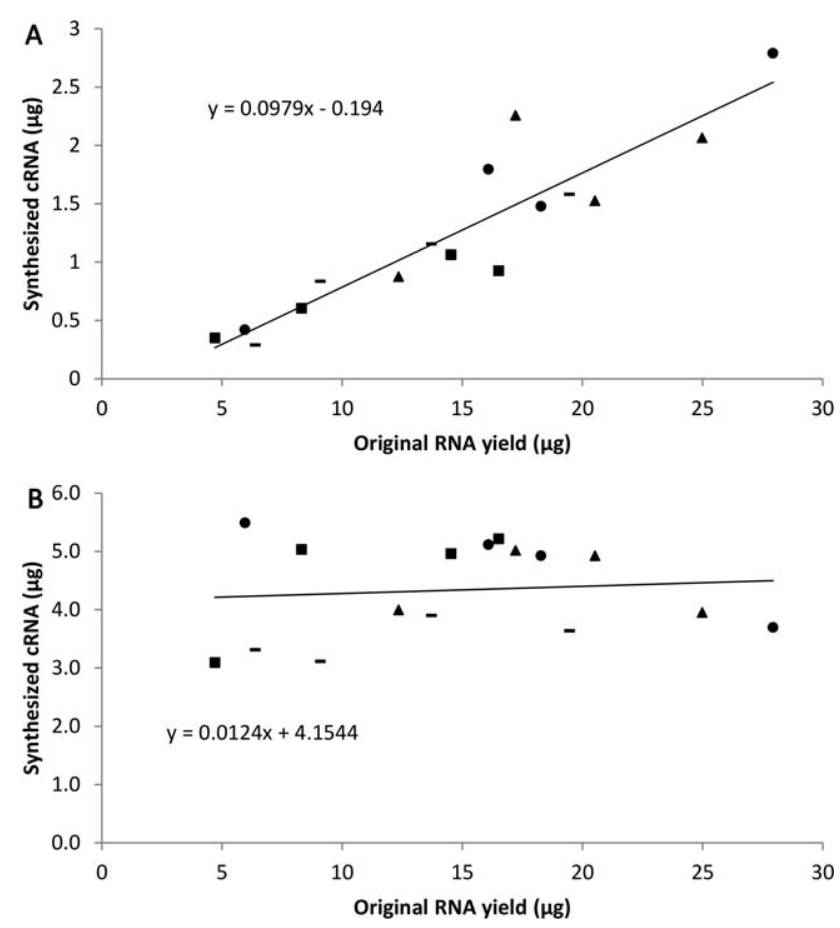

Fig. 1. Scatter plots showing the relationship between fresh sample buffy coat RNA yield and cRNA synthesis yield without $(\mathbf{A})$ and with $(\mathbf{B}) \mathrm{LiCl}$ treatment. Pearson correlation coefficients $(r)$ were 0.91 and 0.10 , respectively. The RT 0 and $3 \mathrm{hr}$ bench time samples are indicated with circles and triangles, while the $-80^{\circ} \mathrm{C} 0$ and $3 \mathrm{hr}$ samples are indicated with squares and dashes, respectively.

spectrophotometric A260/A280 ratio of all samples was good (on average $2.0 \pm 0.1$, where 2 is recommended), while the A260/A230 ratio (on average $1.6 \pm 0.2$, where 2-2.2 is recommended) is indicative of A230 contaminants (Supporting Information Table I). RT samples yielded the highest amount of buffy coat RNA, signifi- cantly higher compared with samples stored at $-80^{\circ} \mathrm{C}$, suggesting that freezing samples influences RNA extraction of blood samples. After following the fluorophore labelling protocol, cRNA synthesis in $25 \%$ of the samples did not meet the minimum level of $0.825 \mu \mathrm{g}$ cRNA recommended by Agilent Technologies and half of these samples were even below the $0.6 \mu \mathrm{g}$ that is needed for microarray hybridization. Although the fluorophore labelling process did reach the minimum recommended level

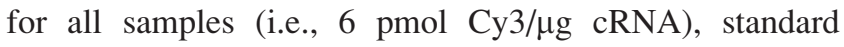
deviations were very high indicating a high variation in the labelling efficiency and 9 of 16 samples were outside the range that our laboratory usually achieves (i.e., 12 to 18 with an average of 15 pmol Cy3/ $\mu \mathrm{g}$ cRNA). Interestingly, RT samples performed best during cRNA synthesis (significantly higher yields than samples stored at $-80^{\circ} \mathrm{C}$ ), similar to what we found for the buffy coat RNA yield. This prompted us to investigate the relationship between original buffy coat sample RNA yield and cRNA synthesis yield; the two variables were found to strongly correlate with each other as shown in Figure 1A $\left(r=0.91, P=7.9 * 10^{-7}\right)$. This indicates that the amount of RNA isolated from an equal amount of starting material (i.e., $400 \mu \mathrm{l}$ of heparin-containing buffy coat) strongly influences the cRNA synthesis rate, even though the amount of input material in the labelling protocol is the same for all samples (i.e., $200 \mathrm{ng}$ RNA).

To demonstrate that the interfering effect observed with heparinized blood is heparin-specific and not related to any other possible contaminations, we performed RNA isolation and the subsequent fluorophore labelling protocol with a set of freshly drawn blood samples collected in tubes containing the anti-coagulants EDTA or citrate (4 subjects, bench times 0 and $3 \mathrm{hr}$, and storage at $-80^{\circ} \mathrm{C}$ ). The overall RIN was good, averaging at $7.3 \pm 0.6$. The A260/A230 
TABLE II. Average Yields and Labelling Efficiencies of Freshly Isolated Buffy Coat Samples Using Heparin, Citrate, or EDTA as Anti-coagulant

\begin{tabular}{lccc}
\hline & $\begin{array}{c}\text { Heparin } \\
\text { samples } \\
(n=8)^{\mathrm{a}}\end{array}$ & $\begin{array}{c}\text { Citrate } \\
\text { samples } \\
(n=8)^{\mathrm{a}}\end{array}$ & $\begin{array}{c}\text { EDTA } \\
\text { samples } \\
(n=8)^{\mathrm{a}}\end{array}$ \\
\hline $\begin{array}{l}\text { Buffy coat RNA } \\
\text { yield }(\mu \mathrm{g})\end{array}$ & $11.6 \pm 5.2$ & $5.4 \pm 2.1^{\mathrm{b}}$ & $5.1 \pm 2.5^{\mathrm{b}}$ \\
$\begin{array}{l}\text { cRNA yield }(\mu \mathrm{g}) \\
\begin{array}{l}\text { Labelling efficiency } \\
\quad(\mathrm{pmol} \mathrm{Cy3/ \mu g} \mathrm{cRNA)}\end{array}\end{array}$ & $0.9 \pm 0.4$ & $4.0 \pm 1.6^{\mathrm{c}}$ & $3.3 \pm 0.6^{\mathrm{c}}$ \\
\hline
\end{tabular}

${ }^{\text {aE}}$ Each anti-coagulant here incorporates two bench times (0 and $3 \mathrm{hr}$ ) for all 4 subjects (i.e. $n=8$ ).

${ }^{\mathrm{b}}$ Significantly lower compared with heparin samples due to half of the volume of buffy coat (Student's $t$-test, $P<0.01$ ).

${ }^{\mathrm{c}}$ Significantly higher compared with heparin samples (Student's $t$-test, $P<0.001)$.

ratios of citrate and EDTA samples were indicative of contaminants (1.2 \pm 0.3 and $1.2 \pm 0.5$, respectively) while the A260/A280 ratios were good $(2.0 \pm 0.1$ and $2.1 \pm 0.1$, respectively, see Supporting Information Table I). Yields and labelling results are summarized in Table II, together with the corresponding results of heparin samples under the same conditions. The cRNA synthesis yield of EDTA and citrate samples (based on an input of 200 ng RNA) was significantly higher than that of heparin samples, and all reached the minimum recommended level of $0.825 \mu \mathrm{g}$ cRNA (3 of 8 heparin samples did not). Labelling efficiencies were also all within the normal range and showed a much lower standard deviation than in heparin samples (2.5 to 5 times lower). There were no differences in cRNA yield or labelling efficiency between bench times for either citrate or EDTA samples and the cRNA yield showed no significant association with the buffy coat RNA yield $(r=0.14$, $P=0.73$ and $r=0.48, P=0.23$ for citrate and EDTA, respectively, results not shown).

To investigate whether $\mathrm{LiCl}$ treatment improved the labelling process of heparinized samples, heparin was removed from the RNA samples by treating them with a $\mathrm{LiCl}$ solution to precipitate the RNA, followed by a repeat of the labelling protocol with the LiCl-treated RNA samples. RNA reference samples were not treated with $\mathrm{LiCl}$ as they are guaranteed free of contaminants (such as heparin, salts, and ethanol) by the manufacturer, and $\mathrm{LiCl}$ is therefore not expected to improve results. $\mathrm{LiCl}$ treatment of heparin samples did not affect the RIN $(8.7 \pm 0.7)$ or the A260/A280 ratios $(2.0 \pm 0.1$, see Supporting Information Table I), whereas the A260/A230 ratios of all heparin samples significantly improved $\left(2.3 \pm 0.1, \quad P=5.8 * 10^{-13}\right)$. cRNA yields significantly increased after $\mathrm{LiCl}$ treatment to levels comparable with the RNA reference controls, regardless of storage temperature or bench time (Table I). The variation in labelling efficiency was also significantly reduced following $\mathrm{LiCl}$ treatment with the overall standard deviation decreasing 6-fold (Table I, "All samples combined" column). A significant increase in labelling efficiency was only found for samples stored at RT. Not coincidentally, this also represented the group of samples with the lowest variation before $\mathrm{LiCl}$ treatment. Heparin removal by $\mathrm{LiCl}$ treatment thus proved very effective, and no significant relationship was found anymore between buffy coat RNA yield and cRNA yield (Fig. 1B, $r=0.10, P=0.71$ ). Direct processing of samples compared with a bench time of $3 \mathrm{hr}$ did not influence buffy coat RNA yield, cRNA synthesis, or labelling efficiency.

To determine whether heparin also affected the reverse transcriptase enzyme during the cDNA synthesis step, the cDNA concentration was also measured during the dye labelling protocol but was not found to differ between groups of samples (cDNA yields of samples without and with $\mathrm{LiCl}$ treatment were $10.7 \pm 0.2$ and $10.8 \pm 0.5 \mu \mathrm{g}$, respectively). Hence, the lower cRNA synthesis in heparin-containing samples can only be attributed to an inhibition of the T7 RNA polymerase in the labelling protocol.

\section{Whole Blood Biobank Sample Work-up and LiCl Treatment}

We subsequently investigated the effect of heparin in whole blood biobank samples to determine whether these samples would also benefit from a $\mathrm{LiCl}$ treatment before microarray hybridization. RNA isolation of cord and follow-up biobank samples proceeded efficiently and RNA was of high quality (RINs of $9.3 \pm 0.2$ and $9.0 \pm 0.5$, respectively). The RNA yield was approximately twice as high in cord samples compared to follow-up samples $(P<0.001$, Table III). After following the fluorophore labelling protocol, we observed a highly significant difference in the amount of generated cRNA and fluorophore labelling efficiency between both sets of samples. Cord samples did not seem to experience an inhibitory effect of heparin during work-up as both the amount of cRNA and the labelling efficiency were well above the minimum recommended values and were within the range that our lab normally obtains. However, a similar relationship between original RNA yield and cRNA yield as previously found for fresh heparin blood samples can still be seen (Fig. 2A, $r=0.75$, $P=0.008)$. In contrast to cord samples, follow-up samples replicated very poorly (all cRNA yields $<0.6 \mu \mathrm{g}$ ) and labelling efficiencies indicate that in most cases labelling did not occur at all (negative values), with the exception of 2 of 12 samples. These two samples were also found to generate the highest amounts of cRNA within the follow-up sample group and corresponded with the highest RNA yields obtained from whole blood. 
Indeed original RNA yield and cRNA yield were also observed to correlate strongly in these samples (Fig. 2B, $r=0.81, P=0.001$ ).

Heparin was subsequently removed from the biobank RNA samples by $\mathrm{LiCl}$ treatment. Although cord sample cRNA was already of good quality, both sample sets were treated to maintain comparability. $\mathrm{LiCl}$ did not affect RNA integrity, which remained very high

TABLE III. Average Yields, RINs, and Labelling Efficiencies of Heparinized Whole Blood Umbilical Cord Samples and Their Corresponding Follow-up Samples

\begin{tabular}{|c|c|c|c|}
\hline & & $\begin{array}{l}\text { Umbilical } \\
\text { cord samples } \\
\quad(n=12)\end{array}$ & $\begin{array}{l}\text { Follow-up } \\
\text { samples } \\
(n=12)\end{array}$ \\
\hline \multirow{3}{*}{$\begin{array}{c}\text { Without } \mathrm{LiCl} \\
\text { treatment }\end{array}$} & $\begin{array}{l}\text { Whole blood RNA } \\
\text { yield }(\mu \mathrm{g})\end{array}$ & $12.9 \pm 3.1$ & $6.4 \pm 2.1^{\mathrm{a}}$ \\
\hline & cRNA yield $(\mu \mathrm{g})$ & $3.0 \pm 1.3$ & $0.3 \pm 0.2^{\mathrm{a}}$ \\
\hline & 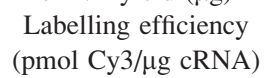 & $15.0 \pm 2.3$ & $-8.6 \pm 17.2^{\mathrm{a}}$ \\
\hline \multirow{2}{*}{$\begin{array}{l}\text { With } \mathrm{LiCl} \\
\text { treatment }\end{array}$} & cRNA yield $(\mu \mathrm{g})$ & $5.8 \pm 0.8^{\mathrm{b}}$ & $3.9 \pm 1.1^{\mathrm{a}, \mathrm{b}}$ \\
\hline & 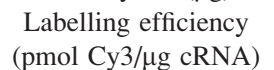 & $19.9 \pm 1.9^{\mathrm{b}}$ & $14.7 \pm 1.0^{\mathrm{a}, \mathrm{b}}$ \\
\hline
\end{tabular}

a Significantly lower in follow-up samples compared with cord samples (paired $t$-test, $P<0.001$ ). Without $\mathrm{LiCl}$ treatment, none of the follow-up samples reached the minimum cRNA yield and only 2 out of 12 reached the minimum labelling efficiency indicated by the manufacturer.

${ }^{\mathrm{b}}$ Significantly higher with $\mathrm{LiCl}$ treatment compared with without (paired $t$-test, $P<0.001)$.
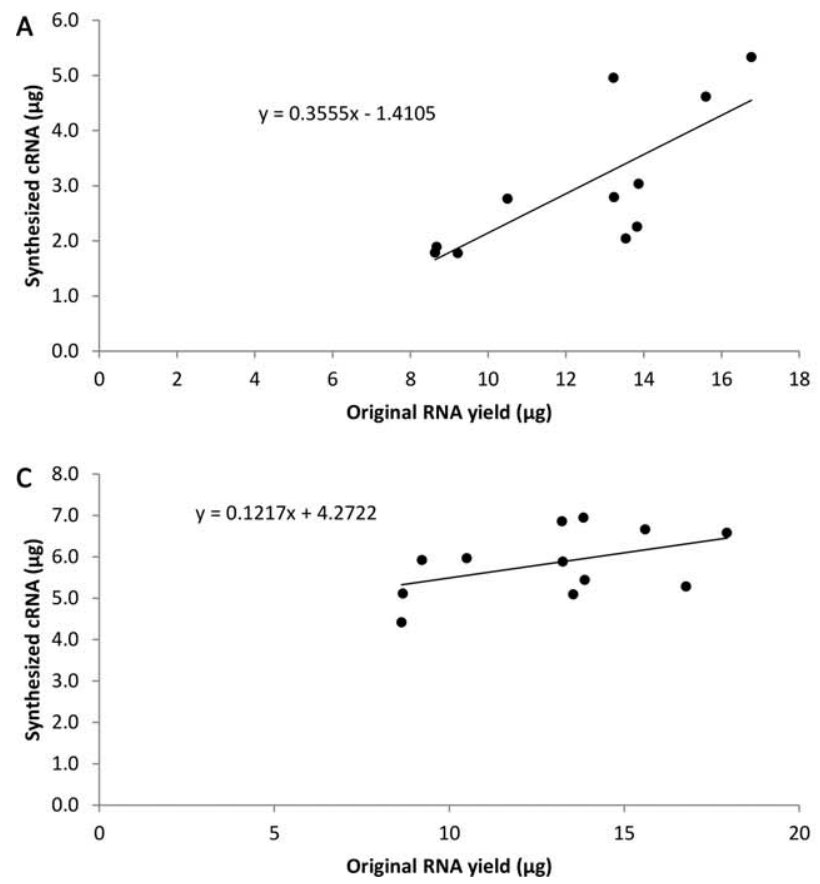

(8.7 \pm 0.7 and $8.4 \pm 0.6$ for cord and follow-up samples, respectively), and the A260/A230 ratios increased significantly in both cord blood and follow-up samples indicating an increase in sample purity $(P<0.01$, Supporting Information Table II). After following the labelling protocol with the LiCl-treated RNA samples, a major significant improvement of both the cRNA yield and labelling efficiencies was observed, with all samples meeting the minimum requirements, thus becoming suitable for microarray hybridization. $\mathrm{LiCl}$ treatment also significantly increased the amount of synthesized cRNA and the labelling efficiency in cord samples, even though these already met the minimum requirements. The correlation between the original whole blood RNA yield and the cRNA yield in both cord and follow-up samples was no longer present after $\mathrm{LiCl}$ treatment $(r=0.47, P=0.12$ and $r=0.11$, $P=0.74$, Figs. 2C and 2D, respectively).

\section{Biobank Samples Microarray Analysis}

After obtaining labelled cRNA that met the recommended standards following $\mathrm{LiCl}$ treatment, biobank samples were hybridized on microarrays, scanned, and processed using our in-house quality control pipeline. Figure 3 and Supporting Information Figure 1 present an overview of graphs generated by the pipeline that provide insight into the quality of the generated gene expression data. For both cord blood and follow-up samples, boxplots of the intensity values that have been corrected for
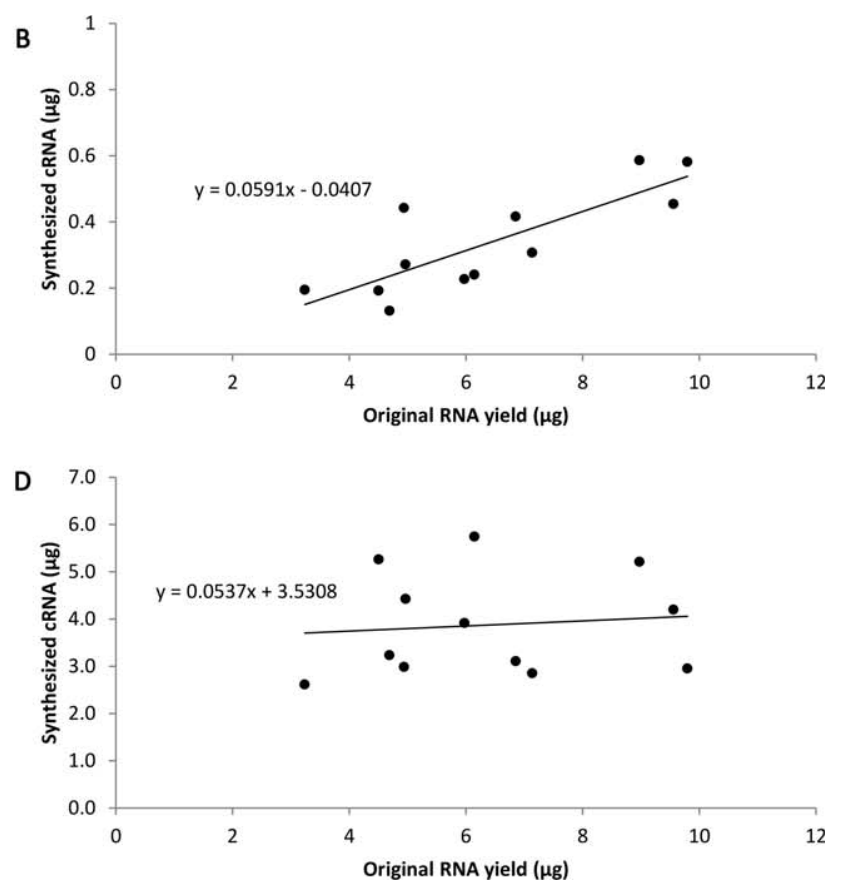

Fig. 2. Scatter plots showing the relationship between whole blood biobank sample RNA yield and cRNA synthesis yield of cord blood and follow-up samples without (A and $\mathbf{B}$, respectively) and with $\mathrm{LiCl}$ treatment ( $\mathbf{C}$ and $\mathbf{D}$, respectively). Pearson correlation coefficients $(r)$ from A to $\mathbf{D}$ were $0.75,0.81,0.47$, and 0.11. In Plot A, one outlier was left out based on a Cook's distance $>4 /(n-2)$. 
A

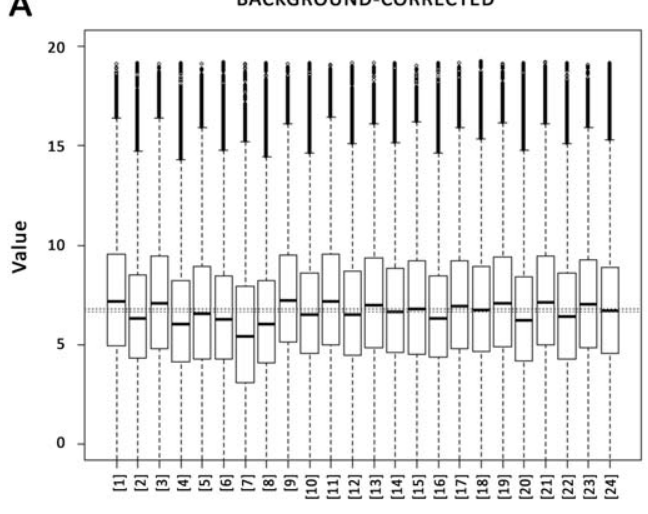

B

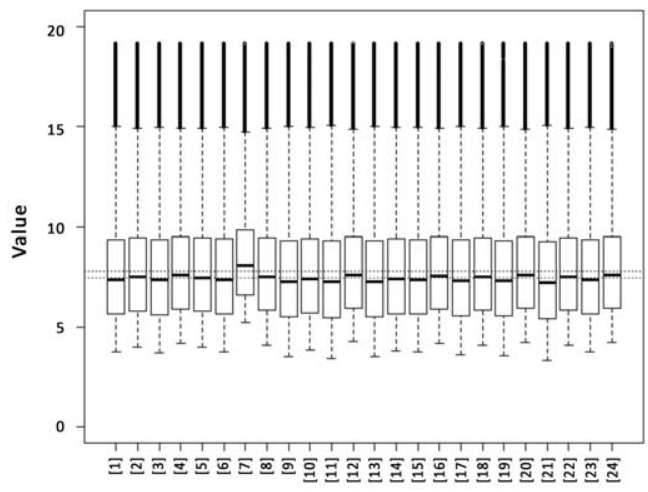

C

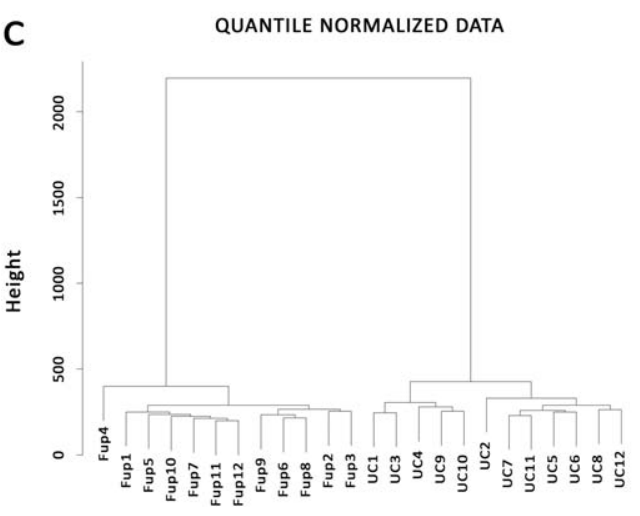

\section{DISCUSSION}

Heparin has previously been described to be an effective inhibitor of PCR [Walter et al., 1967], but this knowledge is not widespread. Contributing to this is the fact that heparin is not always a problematic factor during PCR and varies in the degree of inhibition it causes. In fact, in our recently published study on the usability of long-term storage biobank samples in environmental health research, heparinized blood samples were also analyzed but did not cause any issues during processing [Hebels et al., 2013]. However, more recently we did experience difficulties during fluorophore labelling of RNA derived from heparin blood. In the literature, there are no studies describing the inhibition of fluorophore labelling by heparin, although DNA PCR assays have frequently been reported to be affected [Beutler et al., 1990; Goulian and Heard, 1990; Holodniy et al., 1991; Satsangi et al., 1994; Yokota et al., 1999]. As LiCl treatment is often suggested as an easy and effective heparin-removal strategy, we decided to investigate how $\mathrm{LiCl}$ can improve fluorophore labelling of RNA samples intended for microarray analysis. More importantly, we wanted to assess microarray quality of heparin-purified samples to determine the usability of the gene expression data for omics research. This is especially important considering that many stored biobank buffy coat and whole blood samples were collected using heparin as an anti-coagulant and may thus be unsuitable for transcriptomic analysis.

First, freshly collected buffy coat samples were used to determine the effect of heparin on the fluorophore labelling process in more detail. Heparin samples were found to partially inhibit cRNA synthesis and cause an abnormally high variation in fluorophore labelling efficiency (Table I). No such observations were made in similar samples containing either citrate or EDTA as anticoagulant, showing that this effect is heparin-specific. Moreover, the RNA yield that was initially obtained following RNA isolation of equal volumes of heparinized buffy coat correlated strongly with the eventual amount of synthesized cRNA (Fig. 1A). It has previously been observed that a high DNA-to-heparin ratio (and likewise a high RNA yield-to-heparin ratio), by either increasing clustering analysis of the quantile-normalized intensities
showed a clear distinction between cord and follow-up samples (Fig. 3C) suggesting clear differences in the
expression pattern between the two groups of samples. No abnormal clustering patterns were observed. This is supported by the spot intensity Pearson correlation heatmap provided in Supporting Information Figure 1C, showing strong correlations between samples from the same group and weaker correlations between cord and a close to the reference values considered to be normal. A background levels and those quantile-normalized did arrays that deviate strongly from the bility and high quality data. Both sample groups reach a number of probes that was not well above background and a number of probes defined as "good" (Supporting
Information Figs. $1 \mathrm{~A}$ and $1 \mathrm{~B}$, respectively) that were 
the amount of template DNA or decreasing the concentration of heparin, diminishes the inhibitory effect of heparin during PCR of DNA samples [Taylor, 1997; Yokota et al., 1999]. As heparin is known to exert its inhibitory effect by a direct interaction with the polymerase enzyme [Berg et al., 2002], this would indeed explain why an increase in nucleic acid substrate results in more synthesized copy strands (i.e. competitive inhibition). However, in the fluorophore labelling protocol that we used, the input amount of RNA is exactly the same for each sample (i.e., $200 \mathrm{ng}$ ) yet we still observe a very strong linear relationship between the extracted RNA and synthesized cRNA yield. It has been suggested before that heparin is not only able to interact with polymerases but also with nucleic acids, which are structurally similar. Although heparin and RNA are both negatively charged, binding between the two molecules could be mediated by a divalent cation such as calcium or magnesium, but hydrogen bonding may also be involved [Satsangi et al., 1994; Yokota et al., 1999; Beecher et al., 2014]. A direct association of heparin with the RNA molecules could explain how a lower concentration of RNA in the presence of an equal amount of heparin (i.e., all samples were derived from $400 \mu \mathrm{l}$ buffy coat) would result in a higher heparinsaturation and thus a higher carry-over of heparin than samples with a high RNA concentration, thereby causing a stronger inhibition of polymerase enzymes during the cRNA synthesis step. Another possible explanation for the relationship between RNA yield and cRNA yield is that in samples with a high RNA yield, less heparin can bind to the purification column and subsequently co-elute with the RNA because more column surface binding spots are occupied by RNA. The effect would, however, be the same, i.e., a higher RNA-to-heparin ratio. Interestingly, the downstream effect of the original RNA yield was only observed during cRNA synthesis and not during the preceding cDNA synthesis step. From this, we conclude that only T7 RNA polymerase is affected by heparin and not reverse transcriptase.

Blood samples that were stored at RT were also found to perform significantly better during the labelling process, though still suffering from an inhibitory effect. The RNA yield of frozen samples was significantly lower than that of RT samples, which is commonly observed [Chadderton et al., 1997]. This decreased yield as a result of the freezing process could already increase the carry-over effect of heparin. In addition, damage to the cell membrane due to crystal formation during freezing may also facilitate the interaction between RNA and heparin. It has indeed been suggested previously that whole blood stored for a longer time is more strongly affected by heparin during PCR [Satsangi et al., 1994].

To prevent heparin-induced inhibition of PCRs, LiClmediated precipitation of RNA is most commonly used, although heparinase treatment should work equally well
[Wang et al., 2007]. LiCl treatment was found to improve the results of the fluorophore labelling immensely (Table I). The cRNA synthesis yield and labelling efficiency both reached the level of the non-heparin exposed RNA references and variation in the data decreased to normal values. The previously found correlation between RNA and cRNA yield was no longer found indicating that heparin removal was successful (Fig. 1B). The spectrophotometric A260/A280 and A260/A230 ratios were also monitored as additional indicators of sample purity. Although the A260/A280 ratio remained stable at its recommended value, the A260/A230 ratio, which indicated presence of contaminants before $\mathrm{LiCl}$ treatment, increased strongly afterward (Supporting Information Table I) showing that $\mathrm{LiCl}$ treatment is efficient at removing A230 contaminants still present after column purification. These A230 contaminants do not include heparin which absorbs at $190 \mathrm{~nm}$ and does not influence the A260/A230 ratio at a PCR inhibiting concentration [Gościańska et al., 2011; Covino et al., 2013]. Although contaminants other than heparin could in theory contribute to the downstream PCR interference, the absence of such interference in citrate and EDTA samples, which showed similar low A260/A230 ratios, makes this unlikely. Moreover, in the majority of isolated RNA samples, low A260/A230 ratios can be attributed to the presence of small amounts of guanidine thiocyanate or guanidine hydrochloride (present in RNA isolation kit lysis buffer) and even in extremely high concentrations of up to $100 \mathrm{mM}$ these salts do not compromise the reliability of PCRs [von Alhfen and Schlumpberger, 2010]. In general, low A260/A230 ratios are not correlated with PCR inhibition [Cicinnati et al., 2008]. Nevertheless, LiCl treatment is very effective at purifying RNA from any contaminants still present.

The subsequent processing of biobank samples, which consisted of whole blood umbilical cord samples and their corresponding 4-year venous whole blood follow-up samples showed a distinct difference in fluorophore labelling despite both being heparinized blood. This illustrates that indeed not all heparin-containing samples are affected to the same degree and that in some cases this effect may be missed. RNA extracted from cord blood samples showed both a normal cRNA synthesis as well as fluorophore labelling efficiency, while RNA extracted from follow-up samples replicated very poorly into cRNA and fluorophore labelling was below the detection limit for most samples (Table III). The fact that for most followup samples labelling did not occur at all, but a small amount of cRNA was generated, would indicate that especially Cy3-CTPs are being incorporated into the cRNA strands with difficulty. This indeed seems likely given the lower affinity of polymerases for Cy3-labelled nucleotides [Zhu et al., 1994]. Similar to the freshly processed blood samples, biobank sample RNA yields were also found to correlate strongly with the cRNA yield 
(Figs. 2A and 2B). Interestingly, the effect of heparin is not limited to only follow-up samples. Cord blood samples also show a strong correlation between cRNA and original RNA yield, despite having an average cRNA yield well above the minimum recommended level and with a low variation (Table III). This indicates that heparin still has an effect here but not to an extent that would prevent continuation with sample processing. Although the significant difference in whole blood RNA yield between cord blood and follow-up samples would explain why cord blood samples perform better (i.e., a higher RNA-to-heparin ratio in cord blood samples), it is not entirely clear why these samples have a higher yield. Although the blood volume that was processed was approximately the same for each sample, it is likely that the cord blood samples simply contained a higher concentration of certain cell types, such as hematopoietic stem cells [Lee et al., 2004]. This determining effect of RNA yield would also explain why in our previous study we did not encounter a heparin-associated inhibition during labelling of biobank samples. After extraction, the RNA concentration in those samples was approximately four times higher than the biobank samples investigated here, while having A260/A280 and A260/A230 ratios similar to the samples in this study [Hebels et al., 2013]. Another difference between the cord and follow-up whole blood samples is their time in storage at $-80^{\circ} \mathrm{C}$ (see Material and Methods section), which was significantly longer for cord samples. Although freezing of heparin is not recommended with regard to its stability (product information sheet for heparin sodium salt, Sigma-Aldrich, product number H4748), it is unlikely that a longer freezing time will result in an extensive degradation of heparin.

Although $\mathrm{LiCl}$ treatment to remove heparin was not strictly necessary for cord blood samples given their excellent labelling efficiency, both cord and follow-up samples were treated to rule out any differences in gene expression after microarray hybridization attributable to $\mathrm{LiCl}$ treatment. As expected, both cRNA yield and labelling efficiency increased remarkably in follow-up samples treated with $\mathrm{LiCl}$ (Table III), again reaching the level of non-heparin exposed RNA reference samples (Table I). Cord blood samples also showed a significant increase in both parameters, which is not surprising considering the fact that the cRNA yield also correlated strongly with the original RNA yield and thus still experienced some effect of heparin. After treatment, both sets of biobank samples no longer showed a correlation between RNA yield and cRNA yield suggesting a successful removal of heparin from the RNA samples (Figs. 2C and 2D).

As both cord and follow-up samples reached excellent labelling efficiencies after $\mathrm{LiCl}$ treatment, Cy3-labelled cRNA samples were subsequently used for microarray hybridization. After scanning, a quality control pipeline was used to normalize and assess the quality of the data.
Both types of samples performed as expected, showing numbers of measurable spots around reference values (Supporting Information Figs. 1A and 1B). Boxplots of the intensity values show no strongly deviating microarrays, neither before or after quantile normalization using just background-corrected spots (Figs. 3A and 3B) indicating excellent comparability and high quality data. Cord blood samples can be easily distinguished from follow-up samples as shown by the two separate main clustering branches in Figure 3C and the strong within-samplegroup correlations in Supporting Information Figure 1C. However, there is no indication that this would be caused by any differences in labelling efficiency. As long as the fluorophore labelling process of samples shows a low variation, indicating a stable labelling process, normalization would remove any small effects that still remain. In fact, follow-up samples that showed a lower fluorophore incorporation than cord samples after $\mathrm{LiCl}$ treatment (Table III) even tend to have slightly higher numbers of detected probes (Supporting Information Fig. 1B). Differences between paired samples can therefore only be attributed to actual biological differences in gene expression.

To our knowledge, this is the first time that the inhibiting effect of heparin has been systematically assessed in blood samples intended for microarray analysis. Based on our results, we conclude that heparin can have a detrimental influence on fluorophore labelling by inhibition of T7 RNA polymerase mediated Cy3-labelled cRNA synthesis and that $\mathrm{LiCl}$ treatment restores heparincontaminated RNA samples to more than sufficient quality for labelling reactions. The extent of the effect caused by heparin varies depending on the amount of RNA extracted from the blood, with some samples performing well, while others experience varying degrees of inhibition of cRNA synthesis and Cy3 incorporation. Microarray data of LiCl-treated samples are of high quality and perfectly suitable for downstream data analysis. It is, however, important to note that $\mathrm{LiCl}$ has the downside that small RNAs such as miRNAs, may be lost [Wallace, 1987]. In those cases where miRNA needs to be isolated, a more expensive heparinase treatment would probably be more suitable. Although we only tested the effect of heparin in the labelling protocol for microarrays from Agilent Technologies, it is possible that the labelling protocol of other widely used manufacturers of microarrays such as Affymetrix and NimbleGen will have similar problems. Although Affymetrix and NimbleGen use a different type of labelling, in both labelling protocols a DNA polymerase is used that might be sensitive to heparin inhibition. We therefore strongly recommend that researchers who intend to perform microarray analysis on RNA samples extracted from heparinized whole blood or buffy coats first assess whether a heparin purification either by $\mathrm{LiCl}$ treatment or heparinase treatment is necessary before continuing with the labelling protocol. 
As a supplement to our previous study showing the suitability of biobank blood samples for meaningful omics analysis [Hebels et al., 2013], heparin contamination is not a major issue provided the right steps are taken to eliminate its presence as described here.

\section{AUTHOR CONTRIBUTIONS}

Dr. Hebels designed the study, performed the experiments, analyzed the data, and prepared the draft, including figures and tables, with important intellectual input from Dr. de Kok, Dr. Chalkiadaki, Prof. Kyrtopoulos, and Prof. Kleinjans. Mr. Van Herwijnen, and Mrs. Brauers performed the experiments. Dr. Hebels and Mr. Van Herwijnen had complete access to the study data. Final approval of the version to be published was obtained from all authors.

\section{REFERENCES}

Amersham Biosciences. 2003. Application Note 18-1118-32 AB: Partial Purification of DNA Binding Proteins Using HiTrap Heparin HP. Amersham Biosciences. pp 1-6.

Bai X, Fischer S, Keshavjee S, Liu M. 2000. Heparin interference with reverse transcriptase polymerase chain reaction of RNA extracted from lungs after ischemia-reperfusion. Transpl Int 13:146-150.

Beecher CN, Young RP, Langeslay DJ, Mueller LJ, Larive CK. 2014. Hydroxyl-proton hydrogen bonding in the heparin oligosaccharide Arixtra in aqueous solution. J Phys Chem B 118:482-491.

Berg JM, Tymoczko JL, Stryer L. 2002. Biochemistry, 5th ed. New York, NY: W. H. Freeman. 1050 p.

Beutler E, Gelbart T, Kuhl W. 1990. Interference of heparin with the polymerase chain reaction. Biotechniques 9:166.

Bolstad BM, Irizarry RA, Astrand M, Speed TP. 2003. A comparison of normalization methods for high density oligonucleotide array data based on variance and bias. Bioinformatics 19:185-193.

Chadderton T, Wilson C, Bewick M, Gluck S. 1997. Evaluation of three rapid RNA extraction reagents: Relevance for use in RT-PCR's and measurement of low level gene expression in clinical samples. Cell Mol Biol 43:1227-1234.

Chatzi L, Plana E, Daraki V, Karakosta P, Alegkakis D, Tsatsanis C, Kafatos A, Koutis A, Kogevinas M. 2009. Metabolic syndrome in early pregnancy and risk of preterm birth. Am J Epidemiol 170:829-836.

Cicinnati VR, Shen Q, Sotiropoulos GC, Radtke A, Gerken G, Beckebaum S. 2008. Validation of putative reference genes for gene expression studies in human hepatocellular carcinoma using real-time quantitative RT-PCR. BMC Cancer 8:350.

Coad JE, Lander TA, Litz CE. 1992. Inhibition of restriction endonucleases by common clinical anticoagulants. Anal Biochem 205:368369.

Covino J, Strezoska Z, Kelley M. 2013. Tech Note: Thermo Scientific Solaris RNA Spike Control Kit: Identifying Reaction Inhibition in the RT-qPCR Workflow. Thermo Scientific. pp 1-11.

del Prete MJ, Vernal R, Dolznig H, Mullner EW, Garcia-Sanz JA. 2007. Isolation of polysome-bound mRNA from solid tissues amenable for RT-PCR and profiling experiments. RNA 13:414-421.

Ellinger-Ziegelbauer H, Aubrecht J, Kleinjans JC, Ahr HJ. 2009. Application of toxicogenomics to study mechanisms of genotoxicity and carcinogenicity. Toxicol Lett 186:36-44.
Gerard GF. 1994. Inhibition of SuperScript ${ }^{\mathrm{TM}}$ II reverse transcriptase by common laboratory chemicals. Focus 16:102-103.

Gościańska J, Olejnik A, Sobieszczuk E, Latanowicz K, Nowak I. 2011. Significance of UV-Vis spectroscopy in in vitro release studies. CHEMIK 65:649-654.

Goulian M, Heard CJ. 1990. An inhibitor of DNA polymerases alpha and delta in calf thymus DNA. Nucleic Acids Res 18:4791-4796.

Hebels DG, Georgiadis P, Keun HC, Athersuch TJ, Vineis P, Vermeulen R, Portengen L, Bergdahl IA, Hallmans G, Palli D, Bendinelli B, Krogh V, Tumino R, Sacerdote C, Panico S, Kleinjans JC, de Kok TM, Smith MT, Kyrtopoulos SA. 2013. Performance in omics analyses of blood samples in long-term storage: Opportunities for the exploitation of existing biobanks in environmental health research. Environ Health Perspect 121:480-487.

Holodniy M, Kim S, Katzenstein D, Konrad M, Groves E, Merigan TC. 1991. Inhibition of human immunodeficiency virus gene amplification by heparin. J Clin Microbiol 29:676-679.

Johnson ML, Navanukraw C, Grazul-Bilska AT, Reynolds LP, Redmer DA. 2003. Heparinase treatment of RNA before quantitative realtime RT-PCR. Biotechniques 35:1140-1142, 1144.

Jung R, Lubcke C, Wagener C, Neumaier M. 1997. Reversal of RTPCR inhibition observed in heparinized clinical specimens. Biotechniques 23:24, 26, 28.

Lee OK, Kuo TK, Chen WM, Lee KD, Hsieh SL, Chen TH. 2004. Isolation of multipotent mesenchymal stem cells from umbilical cord blood. Blood 103:1669-1675.

McHale CM, Zhang L, Hubbard AE, Smith MT. 2010. Toxicogenomic profiling of chemically exposed humans in risk assessment. Mutat Res 705:172-183.

Poli F, Cattaneo R, Crespiatico L, Nocco A, Sirchia G. 1993. A rapid and simple method for reversing the inhibitory effect of heparin on PCR for HLA class II typing. PCR Methods Appl 2:356-358.

Satsangi J, Jewell DP, Welsh K, Bunce M, Bell JI. 1994. Effect of heparin on polymerase chain reaction. Lancet 343:1509-1510.

Taylor AC. 1997. Titration of heparinase for removal of the PCRinhibitory effect of heparin in DNA samples. Mol Ecol 6:383-385.

Todd DM, Buccini FJ. 1993. Apparent heparin interference with restriction enzyme digestion of genomic DNA. Clin Chem 39:362-363.

von Alhfen S, Schlumpberger M. 2010. Effects of low A260/A230 ratios in RNA preparations on downstream applications. Qiagen. pp 7-8.

Wallace DM. 1987. Precipitation of nucleic acids. Methods Enzymol 152:41-48.

Walter G, Zillig W, Palm P, Fuchs E. 1967. Initiation of DNAdependent RNA synthesis and the effect of heparin on RNA polymerase. Eur J Biochem/FEBS 3:194-201.

Wang P, Jiang L, Li Y, Chen Z, Meng M, Zou H, Hou Z. 2007. Optimization of test conditions: Heparinase and lithium chloride can reduce the inhibition effect of heparin on $\beta$-actin amplifications during RT-PCR. J Clin Exp Med 6:27-29.

Yokota M, Tatsumi N, Nathalang O, Yamada T, Tsuda I. 1999. Effects of heparin on polymerase chain reaction for blood white cells. J Clin Lab Anal 13:133-140.

Zhu Z, Chao J, Yu H, Waggoner AS. 1994. Directly labeled DNA probes using fluorescent nucleotides with different length linkers. Nucleic Acids Res 22:3418-3422.

Accepted byR. Snyder 